\title{
Desempenho na Fase de Crescimento de Machos Bovinos Inteiros ou Castrados de Diferentes Grupos Genéticos
}

\author{
João Restle1, Dari Celestino Alves Filho², Cristian Faturi ${ }^{3}$, Joilmaro Rodrigo Pereira Rosa ${ }^{4}$, \\ Leonir Luiz Pascoal ${ }^{2}$, Régis Augusto Carvalho Bernardes ${ }^{2}$, Fernando Kuss ${ }^{5}$
}

\begin{abstract}
RESUMO - O objetivo deste experimento foi avaliar, durante a fase de crescimento, o consumo alimentar, ganho de peso e a conversão alimentar de machos inteiros ou castrados, aos oito meses, de dois sistemas de acasalamento, puros (Charolês - C e Nelore - N) e cruzados $\left(1 / 2 \mathrm{CN} \mathrm{e}^{1 / 2} \mathrm{NC}\right)$, bem como medir a heterose resultante. Os animais foram confinados dos nove aos doze meses de idade, sendo todos alimentados com dieta contendo 15\% de proteína bruta e uma relação volumoso:concentrado de 70:30. Não houve diferença entre inteiros e castrados para consumo de matéria seca (CMS), em kg/animal/dia (CMSD), CMS por unidade de peso metabólico (CMSM) e CMS por $100 \mathrm{~kg}$ de peso vivo (CMSP). Os animais inteiros apresentaram 13,7\% a mais de ganho de peso médio diário (GMD) e foram mais eficientes na transformação dos alimentos consumidos em ganho de peso (4,66 contra 4,99 kg de CMS/kg de ganho de peso) que os castrados. O efeito da castração no GMD foi mais pronunciado nos bezerros filhos de touros C (1,00 contra 1,19 kg) que nos filhos de touros $\mathrm{N}(0,91$ contra $0,97 \mathrm{~kg})$. Os animais $\mathrm{F} 1$ apresentaram maior GMD que a média dos puros, resultando em heterose de $9,28 \%$. Os bezerros $\mathrm{C}$ apresentaram maior CMSD e GMD que os N. No entanto, CMSM e CMSP foram similares entre os dois grupos puros. Os animais $1 / 2 \mathrm{CN} \mathrm{e}^{1 / 2} \mathrm{NC}$ não apresentaram diferença frente às variáveis estudadas. Os bezerros filhos de touros $\mathrm{C}$ foram mais eficientes que os filhos de $\mathrm{N}$ na transformação dos alimentos consumidos em ganho de peso.
\end{abstract}

Palavras-chave: castração, Charolês, confinamento, cruzamento, heterose, Nelore

\section{Performance during the Growth Phase of Bulls or Steers from Different Genetic Groups}

\begin{abstract}
The objective of the experiment was to evaluate, during the growth phase, the dry matter intake, weight gain and feed to gain conversion of young bulls and steers, castrated at eight month, from two breeding systems, straightbred (Charolais - C and Nellore - $\mathrm{N}$ ) and crossbred $(1 / 2 \mathrm{CN}, 1 / 2 \mathrm{NC})$, as well as to measure the resulting heterosis. The animals were confined from nine to twelve months and fed a $15 \%$ crude protein diet and a 70:30 forage to concentrate ratio. There was no difference between bulls and steers for dry matter intake (DMI) in kg/animal.day (DMID), DMI per unit of metabolic weight (DMIM) and DMI per $100 \mathrm{~kg}$ of live weight (DMIP). The bulls showed a 13,7\% higher average daily weight gain (ADG) and were more efficient in the feed to gain conversion (4.66 vs $4.99 \mathrm{~kg}$ of DMI $/ \mathrm{kg}$ of gain) than the steers. The effect of castration on the weight gain was more pronounced in calves sired by C bulls ( $1.00 \mathrm{vs} 1.19 \mathrm{~kg}$ ) than in calves sired by N bulls (.91 vs .97 kg). The F1 animals showed higher ADG than the average of the straightbreds, resulting in $9.28 \%$ heterosis. The $\mathrm{C}$ calves presented higher DMID and ADG than the N. However, DMIM and DMIP were similar between the two straightbred groups. The $\mathrm{F} 1 \frac{1}{2} \mathrm{CN}$ and $1 / 2 \mathrm{NC}$ animals did not show difference for the studied variables. The calves sired by $\mathrm{C}$ bulls were more efficient, in the feed to gain conversion, than the calves sired by $\mathrm{N}$ bulls.
\end{abstract}

Key Words: castration, Charolais, crossbreeding, feedlot, heterosis, Nellore

\section{Introdução}

A bovinocultura de corte nacional, para competir no mercado de carnes, terá que buscar alternativas tecnológicas que tornem o sistema de produção mais eficiente e viável economicamente. Uma alternativa é a utilização de machos inteiros para a produção de carne.

A produção de carne a partir de bovinos de corte não-castrados, no Brasil, ainda é baixa, haja vista que a maioria dos frigoríficos discrimina os animais inteiros pelo preço. O menor preço pago pelos animais inteiros é devido ao tipo de animais que são comercializados para o abate. A maioria dos animais inteiros abatidos é touro de descarte, que apresenta carne de coloração escura, além do grande desenvolvimento do quarto anterior, em detrimento do quarto posterior, no qual se localizam os cortes mais nobres da carcaça.

Com a redução da idade de abate dos machos para dois anos ou menos de idade, abre-se nova perspectiva em nosso meio para produzir carne a

\footnotetext{
1 Engㅇ․-Agro-., PhD, Professor Titular, Pesq. do CNPq, Depto de Zootecnia - UFSM, 97105-900, Santa Maria, RS. E.mail: jorestle@ccr.ufsm.br

2 Msc, Professor, Depto de Zootecnia - UFSM.

3 Acadêmico do Curso de Zootecnia - UFSM, BIC - CNPq.

4 Eng으.-Agro., Bolsista de Aperfeiçoamento - UFSM.

5 Acadêmico do Curso de Zootecnia - UFSM, BIC-FAPERGS.
} 
partir de machos não-castrados. Este procedimento é adotado há muito tempo em vários países europeus, nos quais a grande parte da carne consumida é proveniente de bovinos inteiros abatidos com idade inferior a dois anos.

Avaliando o desenvolvimento de machos de corte, mestiços Zebu x Charolês, em condições de pastagem, castrados aos 1,5; 8; ou 12 meses de idade e animais inteiros, RESTLE et al. (1994a) verificaram que, por ocasião do abate aos 25 meses, os animais inteiros pesaram 11; 8; e 7\% a mais que os castrados nas diferentes idades, respectivamente. As diferenças em peso de carcaça quente, citadas no mesma ordem, foram de 13; 10; e 10\% (RESTLE et al., 1994b). Esta é uma diferença importante para o sistema de produção de carne bovina, tendo em vista a praticidade de sua adoção sem custo adicional.

Além de resultarem em maior desenvolvimento e produção de carne, animais inteiros são mais eficientes na conversão alimentar. RESTLE et al. (1997) avaliaram o desempenho em confinamento do desmame, aos sete meses, até o abate, aos catorze meses, de machos Hereford produzidos por vacas de dois anos. Os autores concluíram que os animais inteiros consumiram 14\% menos energia digestível por kg de ganho de peso que os animais castrados aos sete meses.

A produção hormonal proveniente dos testículos apresenta maior efeito na fase em que os animais têm maior incremento de peso, proporcionado pelo melhor nível de alimentação (FIELD, 1971; RESTLE et al., 1994a; e PEREIRA, 1999). Em sistema intensivo de produção, LEE et al. (1990) também constataram que a diferença a favor dos animais inteiros foi mais acentuada na fase de maior velocidade de ganho de peso.

No Brasil, recentemente foram intensas as discussões sobre a liberação do uso de anabolizantes sintéticos para bovinos. O maior questionamento diz respeito à saúde humana. Além de serem produtos naturais e não apresentarem danos à saúde humana, os hormônios androgênicos produzidos por animais inteiros apresentam melhor efeito no incremento do ganho de peso e da eficiência alimentar que os anabolizantes sintéticos testados por LEE et al. (1990).

Ao se recomendar uma tecnologia, quatro pontos são particularmente importantes: a) não prejudicar a saúde humana; b) não causar danos ao meio ambiente; c) ser economicamente viável; d) ser facilmente implantado.

Existem poucas informações no país sobre os efeitos da castração na fase de crescimento, particularmente em animais de diferentes grupos genéticos.
Nesse sentido, o objetivo do presente trabalho foi avaliar o consumo alimentar, o ganho de peso e a conversão alimentar na fase de crescimento de animais inteiros ou castrados dos grupos genéticos Charolês, Nelore e suas cruzas recíprocas, bem como avaliar a heterose resultante desse cruzamento.

\section{Material e Métodos}

O experimento foi conduzido no Departamento de Zootecnia da Universidade Federal de Santa Maria, RS. O município de Santa Maria está situado na região fisiográfica denominada de Depressão Central. Conforme citado por MORENO (1961), o clima da região é subtropical, úmido com possibilidade de estiagem no verão, no qual a temperatura do mês mais quente é superior a $22^{\circ} \mathrm{C}$ e no mês mais frio varia de 3 a $18^{\circ} \mathrm{C}$. A umidade relativa do ar é elevada, variando de 75 a $85 \%$.

Foram utilizados 53 bezerros de dois sistemas de acasalamento puros (Charolês - C e Nelore - N) e cruzados $\left(1 / 2 \mathrm{CN} \mathrm{e}^{1 / 2} \mathrm{NC}\right)$, nascidos no período de parição de setembro a dezembro, sendo os bezerros obtidos de inseminação artificial (período de 45 dias) e de monta natural (período de 45 dias). Durante o período de inseminação, foi utilizado o sêmen de oito touros $\mathrm{C}$ e $\mathrm{N}$ e, para o repasse (RM), quatro touros $\mathrm{C}$ e quatro touros $\mathrm{N}$. Os touros que produziram os bezerros $\mathrm{C}$ foram os mesmos que produziram os $1 / 2 \mathrm{CN}$. Os touros $\mathrm{N}$ que produziram os bezerros $\mathrm{N}$ foram os mesmos que produziram os bezerros $1 / 2 \mathrm{NC}$. Os bezerros de cada grupo genético foram submetidos a um dos seguintes tratamentos:

TC - Bezerros castrados aos oito meses e confinados dos nove aos doze meses;

TI - Bezerros inteiros, confinados dos nove aos doze meses.

Do nascimento aos nove meses de idade, os bezerros foram submetidos às mesmas condições de manejo e nutrição. Os bezerros foram mantidos com as vacas até o desmame, que foi realizado quando os animais apresentavam 90 dias de idade. Após o desmame, os bezerros foram alimentados, durante trinta dias, com uma dieta constituída de capimelefante picado mais farelo de soja, fornecidos em cochos junto aos piquetes onde estavam confinados. Após, passaram para uma pastagem de milheto (Pennisetum americanum), onde permaneceram até os seis meses de idade. Dos seis aos nove meses de idade, os animais foram mantidos em uma área de pastagem nativa, sendo alimentados no cocho com 
1038 Rev. bras. zootec.

cana-de-açúcar picada mais concentrado, em que a relação volumoso:concentrado era de 70:30. No dia primeiro de julho, aos oito meses, os animais foram separados por grupo genético e sorteados para aplicação da castração, a qual foi realizada "a faca" para cortar a pele e membranas protetoras dos testículos; para seccionar o cordão espermático, foi utilizado um hemasculador. Os animais eram revisados diariamente até o 170 dia, quando se constatou a completa cicatrização da ferida causada pelo corte. Vinte e cinco dias após a castração teve início o confinamento.

Os pesos iniciais para os animais inteiros foram de $160,8 \pm 12,29 \mathrm{~kg}(\mathrm{C}), 115,6 \pm 13,7 \mathrm{~kg}(\mathrm{~N}), 138,25 \pm 19 \mathrm{~kg}$ $(1 / 2 \mathrm{CN}), 155,0 \pm 15,9 \mathrm{~kg}(1 / 2 \mathrm{NC})$. Para os animais castrados os pesos iniciais foram de $159,9 \pm 13,7 \mathrm{~kg}$ (C), $118,9 \pm 14,8 \mathrm{~kg}(\mathrm{~N}), 136,0 \pm 19,4 \mathrm{~kg}(1 / 2 \mathrm{CN}) \mathrm{e}$ $159,0 \pm 15,9 \mathrm{~kg}(1 / 2 \mathrm{NC})$.

Os bezerros de cada grupo genético foram desverminados e distribuídos em quatro lotes - dois lotes de animais castrados e dois lotes de animais inteiros. Os animais foram adaptados ao manejo do confinamento e à alimentação durante 10 dias. Após esse período, os bezerros foram pesados (peso inicial), dando início ao período experimental, que teve a duração de 84 dias, dividido em quatro períodos de 21 dias, sendo que no final de cada período os animais eram pesados após um jejum de sólidos de 14 horas.

Os animais foram arraçoados duas vezes ao dia, sendo a metade da dieta fornecida pela manhã $(8 \mathrm{~h})$ e o restante à tarde $(16 \mathrm{~h})$. Diariamente, pela manhã, foram retiradas e pesadas as sobras de alimento do dia anterior, para ajuste da quantidade de alimento que era ofertado, e posterior cálculo de consumo. A quantidade de matéria seca oferecida diariamente foi $10 \%$ superior ao consumo voluntário esperado.

A dieta comum a todos os animais continha na matéria seca oferecida $15 \%$ de proteína bruta. O volumoso utilizado no primeiro período foi silagem de sorgo forrageiro e cana-de-açúcar picada (1:1), enquanto nos demais períodos o volumoso foi a silagem de sorgo forrageiro. O concentrado incluiu farelo de arroz desengordurado, farelo de soja, milho em grão moído, calcário calcítico e sal. A relação volumoso:concentrado foi de 70:30.

As vacinações seguiram o calendário utilizado pelo Departamento de Zootecnia da UFSM, conforme as recomendações da Secretaria da Agricultura do Rio Grande do Sul.

Os dados coletados foram consumo voluntário médio diário de matéria seca (CMS), expresso em $\mathrm{kg} / \mathrm{animal} / \mathrm{dia}$ (CMSD), $\mathrm{kg} / 100 \mathrm{~kg}$ de peso vivo
(CMSP) e g/PV.75 (CMSM), ganho de peso médio diário (GMD) e conversão alimentar (CA).

$\mathrm{O}$ delineamento experimental foi inteiramente casualisado. Efetuaram-se as análises de variância seguindo o modelo estatístico abaixo:

$\mathrm{Y}_{\mathrm{ijk}}=\mu+\mathrm{T}_{\mathrm{i}}+\mathrm{SA}_{\mathrm{i}}+\mathrm{GG}_{\mathrm{k}}\left(\mathrm{SA}_{\mathrm{i}}\right)+\mathrm{E}_{\mathrm{ijk}}$

em que

$\mathrm{Y}_{\mathrm{ijk}} \quad$ = variáveis dependentes;

$\mu \quad=$ média de todas as observações;

$\mathrm{T}_{\mathrm{i}} \quad=$ efeito do estado sexual de ordem $\mathbf{i}$, sendo 1 (inteiros) e 2 (castrados);

$\mathrm{SA}_{\mathrm{j}}=$ efeito de sistema de acasalamento de ordem $\mathbf{j}$, sendo 1 (puros) e 2 (cruzados);

$\mathrm{GG}_{\mathrm{k}}\left(\mathrm{SA}_{\mathrm{i}}\right)=$ efeito de grupo genético de índice $\mathbf{k}$, sendo $\mathbf{k}=1$ (Charolês), 2 (Nelore), $3(1 / 2 \mathrm{CN})$, e 4 (1/2 NC), dentro do sistema de acasalamento de índice j; e

$\mathrm{E}_{\mathrm{ijk}}=$ erro aleatório assumindo distribuição normal com média igual a zero e variância $\sigma^{2}$.

Inicialmente, o modelo estatístico incluiu os efeitos das interações $\mathrm{T}_{\mathrm{i}} * \mathrm{SA}_{\mathrm{j}}$ e $\mathrm{T}_{\mathrm{i}} * \mathrm{GG}_{\mathrm{k}}\left(\mathrm{SA}_{\mathrm{j}}\right)$, no entanto, como os efeitos destas interações foram de baixa magnitude, foram removidas do modelo estatístico final.

Os dados foram analisados pelo método dos quadrados mínimos (SAS, 1993). Quando o F foi significativo $(\mathrm{P}<0,05)$, foi utilizado o teste de comparação de médias com base no teste $t$, no mesmo nível de significância do teste $\mathrm{F}$.

A heterose foi calculada a partir das médias ajustadas como:

$\mathrm{H} \%$ = (média dos cruzados/média dos puros - 1) x 100.

\section{Resultados e Discussão}

Os resultados das análises de variância para os diferentes parâmetros analisados constam da Tabela 1. O consumo voluntário de matéria seca nas diferentes formas de expressão é apresentado na Tabela 2. Verificou-se que não houve diferença entre inteiros e castrados para as três formas de expressar o consumo voluntário de matéria seca. Resultado similar foi relatado por RESTLE et al. (1997). Trabalhando com os mesmos animais, porém na fase de terminação em confinamento dos 20 aos 24 meses de idade, CASACCIA et al. (1993) verificaram maior consumo diário de matéria seca nos animais inteiros em relação aos castrados, o que se deve ao fato de os inteiros terem apresentado maior peso no início da terminação, em função do seu maior ganho de peso dos sete aos vinte meses. Como o consumo é afetado pelo peso dos animais, ao ajustar o CMS para unidade de 
RESTLE et al.

Tabela 1 - Resumo das análises de variância para consumo médio diário de matéria seca, por animal (CMSD), unidade de peso metabólico (CMSM) e $100 \mathrm{~kg}$ de peso vivo (CMSP), ganho de peso médio diário (GMD) e conversão alimentar (CA)

Table 1 - Summary of the analyses of variance for average daily dry matter intake (CMSD), per unit of metabolic size (CMSM) and intake per $100 \mathrm{~kg}$ of live weight (CMSP), average daily weight gain (GMD) and feed:gain ratio $(C A)$

\begin{tabular}{|c|c|c|c|c|c|c|}
\hline \multirow[t]{2}{*}{$\begin{array}{l}\text { Fonte de variação } \\
\text { Source of variation }\end{array}$} & \multirow[t]{2}{*}{$\begin{array}{l}\mathrm{gl} \\
d f\end{array}$} & \multicolumn{5}{|c|}{$\begin{array}{l}\text { Quadrado médio } \\
\text { Mean square }\end{array}$} \\
\hline & & CMSD & CMSM & CMSP & GMD & $\mathrm{CA}$ \\
\hline $\begin{array}{l}\text { Tratamento }(\mathrm{T}) \\
\text { Treatment }\end{array}$ & 1 & 0,2037 & 0,0334 & 0,0163 & $0,0587^{* *}$ & $0,4541^{*}$ \\
\hline $\begin{array}{l}\text { Sistema de acasalamento (SA) } \\
\text { Breeding system }(B S)\end{array}$ & 1 & 0,3939 & 0,0083 & 0,0005 & $0,0339^{*}$ & 0,1061 \\
\hline $\begin{array}{l}\text { Grupo genético }(\mathrm{GG}):(\mathrm{SA}) \\
\text { Genetic group }(G G):(B S)\end{array}$ & 2 & $2,0447^{* *}$ & 0,0253 & 0,0123 & $0,1132^{* *}$ & $0,3080^{*}$ \\
\hline $\begin{array}{l}\text { Erro experimental } \\
\text { Experimental error }\end{array}$ & 11 & 0,0951 & 0,1220 & 0,0060 & 0,0045 & 0,0526 \\
\hline $\mathrm{R}^{2}(\%)$ & & 81,76 & 43,07 & 38,66 & 86,59 & 67,00 \\
\hline $\mathrm{CV}(\%)$ & & 6,33 & 3,44 & 2,94 & 6,60 & 4,76 \\
\hline
\end{tabular}

${ }^{* *} \mathrm{P}<0,01$

${ }^{*} P<0,05$

Tabela 2 - Médias para consumo médio diário de matéria seca, por animal em kg (CMSD), unidade de peso metabólico em g (CMSM) e $100 \mathrm{~kg}$ de peso vivo (CMSP), ganho de peso médio diário em kg (GMD) e conversão alimentar (CA), de acordo com o grupo genético e a condição sexual

Table 2 - Averages for daily dry matter intake per animal in $\mathrm{kg}(C M S D)$, per unit of metabolic size in $\mathrm{g}(\mathrm{CMSM})$, per $100 \mathrm{~kg}$ of live weight (CMSP), average daily weight gain in $\mathrm{kg}(\mathrm{GMD})$ and feed:gain ratio (CA), according to the genetic group and sexual condition

\begin{tabular}{|c|c|c|c|c|c|}
\hline \multicolumn{3}{|c|}{$\begin{array}{l}\text { Condição sexual/Grupo genético } \\
\text { Sexual condition/Genetic group }\end{array}$} & \multicolumn{3}{|c|}{$\begin{array}{l}\text { Variáveis } \\
\text { Variables }\end{array}$} \\
\hline & CMSD & CMSM & CMSP & GMD & CA \\
\hline \multicolumn{6}{|l|}{ Inteiros } \\
\hline \multicolumn{6}{|l|}{ Intact } \\
\hline Charolês (C) & $5,62^{\mathrm{a}}$ & $100,93^{a}$ & $2,64^{\mathrm{a}}$ & $1,23^{\mathrm{a}}$ & $4,55^{\mathrm{a}}$ \\
\hline \multicolumn{6}{|l|}{ Charolais } \\
\hline Nelore (N) & $4,08^{\mathrm{a}}$ & $95,05^{\mathrm{a}}$ & $2,71^{\mathrm{a}}$ & $0,83^{\mathrm{a}}$ & $4,93^{\mathrm{a}}$ \\
\hline \multicolumn{6}{|l|}{ Nellore } \\
\hline $1 / 2 \mathrm{CN}$ & $4,93^{\mathrm{a}}$ & $97,78^{\mathrm{a}}$ & $2,65^{\mathrm{a}}$ & $1,14^{\mathrm{a}}$ & $4,34^{\mathrm{a}}$ \\
\hline $1 / 2 \mathrm{NC}$ & $5,29^{a}$ & $98,99^{a}$ & $2,63^{\mathrm{a}}$ & $1,10^{\mathrm{a}}$ & $4,80^{\mathrm{a}}$ \\
\hline Médias & $4,98^{\mathrm{A}}$ & $98,19^{\mathrm{A}}$ & $2,66^{\mathrm{A}}$ & $1,08^{\mathrm{A}}$ & $4,66^{\mathrm{A}}$ \\
\hline \multicolumn{6}{|l|}{ Means } \\
\hline \multirow{2}{*}{\multicolumn{6}{|c|}{$\begin{array}{l}\text { Castrados } \\
\text { Castrated }\end{array}$}} \\
\hline & & & & & \\
\hline Charolês (C) & $5,11^{\mathrm{a}}$ & $94,86^{\mathrm{a}}$ & $2,51^{\mathrm{a}}$ & $1,04^{\mathrm{b}}$ & $4,92^{\mathrm{a}}$ \\
\hline \multicolumn{6}{|l|}{ Charolais } \\
\hline Nelore (N) & $4,03^{\mathrm{a}}$ & $93,25^{\mathrm{a}}$ & $2,66^{\mathrm{a}}$ & $0,76^{\mathrm{a}}$ & $5,22^{\mathrm{a}}$ \\
\hline \multicolumn{6}{|l|}{ Nellore } \\
\hline $1 / 2 \mathrm{CN}$ & $4,55^{\mathrm{a}}$ & $93,78^{\mathrm{a}}$ & $2,57^{\mathrm{a}}$ & $0,97^{\mathrm{b}}$ & $4,70^{\mathrm{a}}$ \\
\hline $1 / 2 \mathrm{NC}$ & $5,33^{\mathrm{a}}$ & $99,30^{\mathrm{a}}$ & $2,63^{\mathrm{a}}$ & $1,04^{\mathrm{a}}$ & $5,12^{\mathrm{a}}$ \\
\hline Médias & $4,76^{\mathrm{A}}$ & $95,30^{\mathrm{A}}$ & $2,59^{\mathrm{A}}$ & $0,95^{\mathrm{B}}$ & $4,99^{\mathrm{B}}$ \\
\hline
\end{tabular}

Médias, na coluna, seguidas por letras minúsculas diferentes na comparação entre inteiros e castrados para 0 mesmo grupo genético, são diferentes $(P<0,05)$ pelo teste $t$.

Médias, na coluna, seguidas por letras maiúsculas diferentes, na comparação entre inteiros e castrados, são diferentes $(P<0,05)$ pelo teste $t$.

Means, within a column, followed by small different letters for the comparison between intact and castrated, for the same genetic group, are different $(P<.05)$ by $t$ test.

Means, within a column, followed by capital different letters for the comparison between intact and castrated are different $(P<.05)$ by $t$ test. 
1040 Rev. bras. zootec.

tamanho metabólico, a diferença foi eliminada.

A média do CMS ajustado para tamanho metabólico verificada no presente estudo $(96,7 \mathrm{~g})$ foi similar aos $97,1 \mathrm{~g}$ verificados por FLORES et al. (1997) para animais inteiros da raça Hereford, terminados em confinamento aos 14 meses, porém foram inferiores aos valores médios de inteiros e castrados (107 g) encontrados por CASACCIA et al. (1993) e aos relatados por RESTLE et al. (1997) para animais inteiros $(106,1 \mathrm{~g})$ e castrados $(109,1 \mathrm{~g})$ da raça Hereford terminados em confinamento aos 14 meses de idade. Ao comparar o CMS entre diferentes trabalhos de pesquisa, mesmo ajustando o CMS para tamanho metabólico dos animais, podem ocorrer diferenças entre trabalhos. Segundo MERTENS (1992), o consumo de alimento é regulado por vários fatores referentes ao animal (peso vivo, nível de produção, estado fisiológico, entre outros), ao alimento (fibra, demanda energética, volume etc) e às condições de alimentação (disponibilidade de alimento, freqüência de alimentação, tempo de acesso ao alimento etc). Além disso, fatores ambientais aos quais o animal está exposto também podem afetar o consumo (NRC, 1996).

$\mathrm{Na}$ Tabela 2, pode ser observado que os animais inteiros apresentaram ganho de peso médio diário (GMD) superior aos castrados (1,08 contra $0,95 \mathrm{~kg})$, representando uma diferença de $13,7 \%$. Maior GMD em animais inteiros foi reportado por ARTHAUD et al. (1977), que trabalharam com animais abatidos aos 15 meses $(0,96$ contra $0,75 \mathrm{~kg})$, sendo a diferença de 28\%. RESTLE et al. (1997), confinando bezerros Hereford inteiros e castrados aos sete meses para abate aos 14 meses, verificaram diferença similar no GMD (12,8\%) à do presente experimento, porém com maiores ganhos de peso para inteiros $(1,23 \mathrm{~kg}) \mathrm{e}$ castrados $(1,09 \mathrm{~kg})$.

RESTLE et al. (1994a) conduziram um trabalho em condições de pastagem, onde foram estudadas diferentes idades de castração, entre elas a castração aos 1,5 meses e 8 meses de idade. Os autores verificaram que até os 8 meses de idade não houve diferença entre castrados e inteiros. Já dos 8 aos 12 meses a diferença no GMD entre os inteiros e os castrados aos oito meses foi de $12 \%$ a favor dos inteiros. Observa-se a similaridade na diferença do GMD entre o presente trabalho e o conduzido por RESTLE et al. (1994a), ambos na fase de crescimento dos animais. Maiores ganhos de peso na fase de crescimento em animais inteiros, em relação a animais castrados por diferentes métodos, também foram verificados por RESTLE et al. (1996). LEE et al.
(1990) relataram que, com a castração, há redução no crescimento dos animais, em função do efeito adverso desta sobre os hormônios androgênicos, principalmente a testosterona, que, quando presente, proporciona melhor anabolismo do nitrogênio endógeno. Diferenças acentuadas no GMD durante o confinamento, entre inteiros e castrados aos sete meses, foram relatados por MORGAN et al. (1993). Esses autores reportaram, em seu trabalho, que os animais castrados apresentaram maior excreção de Nt-metilhistidina, que, combinada com massa muscular esquelética menor ou igual, indica maiores índices de degradação da proteína muscular.

A conversão alimentar foi maior nos animais castrados, o que indica que os animais inteiros foram mais eficientes na transformação do alimento em ganho de peso. Os animais inteiros consumiram 6,6\% menos alimento que os castrados para adicionar $1 \mathrm{~kg}$ no peso vivo. Verifica-se, portanto, a importância da testosterona produzida pelos testículos não só no ganho de peso, mas também na eficiência alimentar. A melhor eficiência alimentar dos inteiros é muito importante principalmente nos sistemas que utilizam o confinamento para produção de carne, já que a alimentação representa mais de $70 \%$ do custo desse processo.

Melhor eficiência alimentar para animais inteiros também foi relatada por RESTLE et al. (1997), porém com valores maiores para conversão alimentar tanto para inteiros $(5,8)$ como para castrados $(6,8)$. MORGAN et al. (1993) observaram que os animais inteiros foram sempre mais eficientes que os castrados, à medida que os primeiros ganharam mais peso com a mesma unidade alimentar (kg MS).

Apesar de não haver interação significativa entre T x GG (SA) para as variáveis estudadas, verifica-se, na Tabela 2, que os efeitos da castração no GMD foram mais evidentes nos animais $\mathrm{C} \mathrm{e} 1 / 2 \mathrm{CN}$. O GMD dos animais $C$ inteiros foi superior $(18,3 \%)$ aos castrados $(1,23$ contra $1,04 \mathrm{~kg} ; \mathrm{P}<0,05)$; também nos $1 \frac{1}{2} \mathrm{CN}$ o GMD dos inteiros foi superior $(17,5 \%)$ ao dos castrados $(1,14$ contra $0,97 \mathrm{~kg} ; \mathrm{P}<0,05)$. Já nos demais grupos genéticos, a diferença no GMD entre inteiros e castrados foi menos evidente, sendo de $9,2 \% \operatorname{nos} \mathrm{N}$ $(0,83$ contra $0,76 \mathrm{~kg} ; \mathrm{P}>0,05)$ e de $5,8 \%$ nos $1 / 2 \mathrm{NC}$ $(1,10$ contra $1,04 \mathrm{~kg} ; \mathrm{P}>0,05)$. Verificou-se que, quando a raça do pai dos bezerros foi o $\mathrm{C}$, a diferença entre inteiros e castrados foi de $19 \%$ ( 1,19 contra $1,00 \mathrm{~kg}$; $\mathrm{P}<0,05)$. Entretanto, quando a raça do pai dos bezerros foi o $\mathrm{N}$, a diferença entre inteiros e castrados caiu para $6,6 \%(0,97$ contra $0,91 \mathrm{~kg} ; \mathrm{P}>0,05)$.

Uma possível explicação para o maior efeito da 
castração no GMD dos animais filhos de touros C é o desenvolvimento dos testículos nos quais a testosterona é produzida. PEREIRA (1999) avaliou o desenvolvimento dos testículos, por intermédio do perímetro escrotal de animais $\mathrm{C}$ e N. Foi constatado que, do desenvolvimento total do perímetro escrotal no $\mathrm{C}$ dos 8 aos 24 meses, $57,31 \%$ ocorreram na fase dos 8 aos 12 meses; já no $\mathrm{N}$, no mesmo período, o desenvolvimento representou $33,71 \%$. Os animais $\mathrm{C}$ foram mais precoces no crescimento dos testículos que os N. Outro aspecto a ser considerado é que os animais $\mathrm{C}$ apresentam elevado potencial de ganho de peso, sendo a composição do ganho principalmente de tecido muscular com elevada concentração de proteína. Como a testosterona atua sobre o anabolismo do nitrogênio endógeno, é provável que animais com maior potencial de crescimento muscular sejam mais afetados pela remoção das gônodas.

$\mathrm{Na}$ Tabela 3, constam os resultados referentes ao sistema de acasalamento e os grupos genéticos. Numericamente o CMSD foi maior $(\mathrm{P}=0,0666)$ nos mestiços F1, no entanto, quando o consumo foi ajustado para $100 \mathrm{~kg}$ de peso vivo ou para tamanho metabólico, a diferença foi eliminada. RESTLE et al. (1995), comparando animais C, N, $1 / 2 \mathrm{CN}$ e $1 / 2 \mathrm{NC}$ na fase de terminação em confinamento dos 20 aos 25 meses, verificaram que os animais mestiços F1 apresentaram $15,43 \%$ a mais no CMSD que os puros, sendo a diferença superior aos $6,57 \%$ verificados no presente trabalho. Quando aqueles autores ajustaram o CMS para tamanho metabólico, a diferença caiu para 0,66\%. Segundo RESTLE e VAZ (1999), o consumo de alimentos por parte do animal é de fundamental importância, pois representa mais de $70 \%$ do custo do confinamento e, por meio do consumo do alimento, é que o organismo do animal vai ter a disposição os nutrientes necessários para promover o crescimento e/ou engorda. Daí a importância em se medir o CMSD, pois está diretamente relacionado com o GMD.

Maior consumo de alimentos pelos animais cruzados em relação aos definidos foi citado por KOGER (1973), trabalhando com animais Shorthorn e Brahman puros e cruzados em confinamento. Resultados similares foram citados por RESTLE et al. (1999), em que animais cruzados $5 / 8$ Hereford $(\mathrm{H}) 3 / 8 \mathrm{Ne}^{1 / 2} \mathrm{H}^{1 / 2} \mathrm{~N}$ consumiram mais MS que os animais $\mathrm{H}$ puros.

Tabela 3 - Médias para consumo médio diário de matéria seca por animal em kg (CMSD), por unidade de peso metabólico em g (CMSM) e $100 \mathrm{~kg}$ de peso vivo (CMSP), ganho de peso médio diário em kg (GMD) e conversão alimentar (CA), de acordo com sistema de acasalamento e grupo genético

Table 3 - Averages for daily dry matter intake per animal in $\mathrm{kg}(C M S D)$, per unit of metabolic size in $\mathrm{g}(C M S M)$, per $100 \mathrm{~kg}$ of live weight (CMSP), average daily weight gain in $\mathrm{kg}(\mathrm{GMD})$ and feed:gain (CA), according to breeding system and genetic group

\begin{tabular}{|c|c|c|c|c|c|}
\hline \multirow[t]{2}{*}{$\begin{array}{l}\text { Grupo genético } \\
\text { Genetic group }\end{array}$} & \multicolumn{5}{|c|}{$\begin{array}{l}\text { Variáveis } \\
\text { Variables }\end{array}$} \\
\hline & CMSD & CMSM & CMSP & GMD & CA \\
\hline Charolês (C) & $5,37^{\mathrm{a}}$ & $97,89^{a}$ & $2,56^{\mathrm{a}}$ & $1,14^{\mathrm{a}}$ & $4,74^{\mathrm{a}}$ \\
\hline $\begin{array}{l}\text { Charolais } \\
\text { Nelore (N) }\end{array}$ & $4,06^{\mathrm{b}}$ & $94,15^{\mathrm{a}}$ & $2,69^{\mathrm{a}}$ & $0,80^{\mathrm{b}}$ & $5,07^{\mathrm{a}}$ \\
\hline $\begin{array}{l}\text { Nellore } \\
\text { Média dos puros } \\
\text { Straightbredmean }\end{array}$ & $4,72^{\mathrm{A}}$ & $96,02^{\mathrm{A}}$ & $2,63^{\mathrm{A}}$ & $0,97^{\mathrm{B}}$ & $4,91^{\mathrm{A}}$ \\
\hline $\begin{array}{l}1 / 2 \mathrm{CN} \\
1 / 2 \mathrm{NC} \\
\text { Média dos cruzados } \\
\text { Crossbred mean }\end{array}$ & $\begin{array}{l}4,74^{\mathrm{a}} \\
5,31^{\mathrm{a}} \\
5,03^{\mathrm{A}}\end{array}$ & $\begin{array}{l}95,78^{\mathrm{a}} \\
99,14^{\mathrm{a}} \\
97,46^{\mathrm{A}}\end{array}$ & $\begin{array}{l}2,61^{\mathrm{a}} \\
2,63^{\mathrm{a}} \\
2,61^{\mathrm{A}}\end{array}$ & $\begin{array}{l}1,05^{\mathrm{a}} \\
1,07^{\mathrm{a}} \\
1,06^{\mathrm{A}}\end{array}$ & $\begin{array}{l}4,52^{\mathrm{a}} \\
4,96^{\mathrm{a}} \\
4,74^{\mathrm{A}}\end{array}$ \\
\hline Heterose (\%) & 6,57 & 1,50 & $-0,01$ & 9,28 & $-3,46$ \\
\hline
\end{tabular}

Heterosis

Médias, na coluna, seguidas por letras minúsculas diferentes na comparação entre Charolês e Nelore ou entre $1 / 2$ CN e $1 / 2 \mathrm{NC}$, diferem $(\mathrm{P}<0,05)$ pelo teste $t$.

Médias, na coluna, seguidas por letras maiúsculas diferentes na comparação entre puros e mestiços diferem $(P<0,05)$ pelo teste $t$.

Means, within a column, followed by different small letters for comparison between Charolais and Nellore or $1 / 2 \mathrm{CN}$ and $1 / 2 \mathrm{NC}$, are different $(P<.05)$ by $t$ test.

Means, within a column, followed by different capital letters for the comparison between straightbred and crossbred, are different $(P<.05)$ by $t$ test. 
1042 Rev. bras. zootec.

Avaliando os grupos genéticos dentro do sistema de acasalamento, verifica-se que os bezerros $\mathrm{C}$ apresentaram maior CMSD que os $\mathrm{N}(5,37$ contra $4,06 \mathrm{~kg}$; $\mathrm{P}<0,05$ ), o que representa diferença de $32 \%$. Comparando animais $\mathrm{C}$ e $\mathrm{N}$ na fase de terminação, dos 20 aos 24 meses, RESTLE et al. (1995) obtiveram diferença similar (34\%) no CMS. Consumo de matéria seca mais elevado em diferentes grupos genéticos de Bos taurus frente ao Nelore foi citado por RESTLE e VAZ (1999). Segundo os mesmos autores, o maior consumo de alimentos verificado pelas raças européias frente ao Nelore é o reflexo da intensa seleção para ganho de peso, já que incrementos de ganho de peso implicam em maior consumo de alimentos.

Ao ajustar o CMS para unidade de peso metabólico, a diferença entre o $\mathrm{C}$ e $\mathrm{N}$ reduziu e passou a ser não-significativa $(97,89$ contra $94,15 \mathrm{~g}$; $\mathrm{P}>0,05)$. RESTLE et al. (1995) também verificaram que o CMSM para $\mathrm{C}$ e $\mathrm{N}$ passou a não ser significativo, porém com diferença maior (116,5 contra $96,0 \mathrm{~g})$.

Ao comparar os animais $\mathrm{F} 1 \frac{1}{2} \mathrm{CN}$ e $1 / 2 \mathrm{NC}$, verifica-se comportamento similar entre os dois grupos genéticos nas três formas de expressar o CMS. Observação similar é relatada no trabalho de RESTLE et al. (1995), no qual, na fase de terminação, o CMSD foi 9,58 e $9,57 \mathrm{~kg}$ para $1 / 2 \mathrm{CN}$ e $1 / 2 \mathrm{NC}$ e o CMSM, de 104 e $110 \mathrm{~g}$, respectivamente.

Quanto ao GMD, verifica-se na Tabela 3 que os animais $\mathrm{F} 1$ foram superiores à média dos puros $(1,06$ vs $0,97 \mathrm{~kg} ; \mathrm{P}<0,05)$. Superioridade no GMD de mestiços oriundos do cruzamento de reprodutores de raças européias continentais com $\mathrm{N}$, frente aos animais $\mathrm{N}$ puros, foi relatada por GALVÃO (1991) e EUCLIDES FILHO et al. (1997). No entanto, existe pouca informação no Brasil sobre a comparação de animais mestiços F1, oriundos de cruzamento recíproco, com a média dos animais puros. Constatou-se heterose de 9,28\% para GMD. Em geral, os valores de heterose para ganho de peso em confinamento são baixos principalmente na fase de terminação (RESTLE et al., 1995). No entanto, na fase de crescimento em condições de pastagem, RESTLE et al. (1999) observaram valores expressivos de heterose para mestiços $(1 / 2 \mathrm{CN}$ e $1 / 2 \mathrm{NC})$. Os autores relataram heterose de 26,2\% no GMD dos sete aos doze meses, quando os animais foram mantidos em pastagem cultivada de inverno. JOHNSTON et al. (1992) citaram baixos valores de heterose para as características de desempenho pós-desmame. De acordo com KOGER (1980), nos cruzamentos em que se utilizam duas raças européias, como foi o caso do trabalho de
JOHNSTON et al. (1992), a heterose resultante é, na média, três vezes menor que a obtida no cruzamento de uma raça européia com uma zebuína, que foi o caso do presente trabalho.

Ao comparar o GMD dos animais puros, verifica-se na Tabela 3 o maior ganho de peso dos $\mathrm{C}$ em relação aos $\mathrm{N}(1,14$ contra $0,80 \mathrm{~kg}$; $\mathrm{P}<0,05)$. O maior GMD do $\mathrm{C}$ mostra a maior frequência de genes para ganho de peso que esta raça apresenta em relação ao N, o que fica mais evidente, quando o GMD é comparado com os animais $\mathrm{F} 11 / 2 \mathrm{CN} \mathrm{e}^{1 / 2} \mathrm{NC}$. Maior GMD para animais $\mathrm{C}$ frente ao $\mathrm{N}$ foi também relatado por MOLETTA e RESTLE (1992), utilizando animais em confinamento alimentados com dieta contendo baixa concentração energética (2270 kcal ED/kg MS) e relação volumoso:concentrado de 72:28. Maior GMD para $\mathrm{C}$ frente ao $\mathrm{N}$ também foi relatado por RESTLE et al. (1995), quando utilizaram dietas com concentração energética mais elevada e relação volumoso:concentrado de 55:45.

Conforme pode ser observado na Tabela 3, o GMD dos animais $1 / 2 \mathrm{CN} 1 / 2_{2} \mathrm{NC}$ foi muito similar, mostrando que nesta fase o efeito materno foi pequeno, o que, em parte, pode ser explicado pela idade de desmame, realizado aos três meses.

A conversão alimentar foi similar entre puros e mestiços $(4,91$ contra 4,74; $\mathrm{P}>0,05)$. Os mestiços, embora tenham apresentado maior CMSD, mostraram maior GMD, o que resultou em diferença, nãosignificativa, de $3,46 \%$ a menos de alimento consumido por kg de ganho de peso para os mestiços. Também não houve diferença significativa entre os grupos genéticos dentro de sistema de acasalamento. Com exceção do $\mathrm{N}$, todos o grupos genéticos apresentaram conversão alimentar inferior a 5 , que pode ser considerada boa eficiência alimentar.

Comparando os bezerros filhos de touros $\mathrm{C}$ com os filhos de touros N, quanto à conversão alimentar, verificou-se que os filhos de $\mathrm{C}$ foram mais eficientes na transformação de matéria seca consumida em ganho de peso $(4,63$ contra 5,$02 ; \mathrm{P}<0,05)$.

\section{Conclusões}

Animais inteiros apresentaram maior ganho de peso médio diário e foram mais eficientes na transformação de alimento em ganho de peso que os castrados.

A castração afetou mais o ganho de peso dos bezerros filhos de touros Charolês que os filhos de touros Nelore.

Bezerros filhos de touros Charolês foram mais 
eficientes na transformação de alimento em ganho de peso que filhos de touros Nelore.

Animais mestiços F1 apresentaram maior ganho de peso que os puros, resultando em heterose expressiva.

\section{Referências Bibliográficas}

ARTHAUD, V.H., MANDIGO, R.W., KOCH, R.M. et al. 1977. Carcass composition and palatability attributes of bulls and steers fed different energy levels and killed at four ages. J. Anim. Sci., 44(1):53-64.

CASACCIA, J.L., PIRES, C.C., RESTLE, J. Confinamento de bovinos inteiros ou castrados de diferentes grupos genéticos. In: REUNIÃO ANUAL DA SOCIEDADE BRASILEIRA DE ZOOTECNIA, 30, Rio de Janeiro, 1993. Anais... Rio de Janeiro: SBZ, 1993. p.468.

EUCLIDES FILHO, K., EUCLIDES, V.P.B., FIGUEREIDO, G.R. de et al. 1997. Avaliação de animais nelore e seus mestiços com Charolês, Fleckvieh e Chianina, em três dietas. 1. Ganho de peso e conversão alimentar. R. Bras. Zootec., 26(1):66-72.

FIELD, R.A. 1971. Effect of castration on meat quality and quantity. J. Anim. Sci., 32(5):849-857.

FLORES, J.L.C. Desempenho em confinamento e características de carcaça e da carne de machos inteiros de diferentes grupos genéticos na fase do desmame ao abate aos quatorze meses. Santa Maria, RS: UFSM, 1997. 109p. Dissertação (Mestrado em Zootecnia) - Universidade Federal de Santa Maria, 1997.

GALVÃO, J.G. Estudo da eficiência nutritiva, característica e composição física de carcaça de bovinos de três grupos raciais, abatidos em três estágios de maturidade. Viçosa, MG: UFV, 1991. 81p. Dissertação (Mestrado em Zootecnia) - Universidade Federal de Viçosa, 1991.

JOHNSTON, D.J., THOMPSON, J.M., HAMMOND, K. 1992. Additive and nonadditive differences in post weaning growth and carcass characteristics of Devon, Hereford and reciprocal cross steers. J. Anim. Sci., 70(9):2688-2694.

KOGER, M. 1973. Summary. In: KOGER, M., CUNHA, T.J., WARNICK, A.C. (Eds.) Crossbreeding beef cattle. Gainesville: University of Florida Press. p.434-453.

KOGER, M. 1980. Effective crossbreeding systems utilizing Zebu cattle. J. Anim. Sci., 50(6):1215-1220.

LEE, C.Y., HENRICKS, D.M., SKELLEY, G.C. et al. 1990. Growth and hormones response of intact and castrate male cattle to trenbolone acetate and estradiol. J. Anim. Sci., 68(9):2682-2689.

MERTENS, D.R. Análise da fibra e sua utilização na avaliação de alimentos e formulação de rações. In: SIMPÓSIO INTERNACIONAL DE RUMINANTES, REUNIÃO ANUAL SOCIEDADE BRASILEIRA DE ZOOTECNIA, 29, Lavras, 1992. Anais... Lavras: SBZ, 1992, p.188-219.
MOLETTA, J.L., RESTLE, J. 1992. Desempenho em confinamento de novilhos de diferentes grupos genéticos. Ciência Rural, 22(2):227-233.

MORENO, J.A. 1961. Clima do Rio Grande do Sul. Porto Alegre: Secretaria da Agricultura. 41p.

MORGAN, J.B., WHEELER, T.L., KOOHMARAIE, M. et al. 1993. Effect of castration on myofibrillar protein turnover, endogenous proteinase activities, and muscle growth in bovine skeletal muscle. J. Anim. Sci., 71(2):408-414.

NATIONAL RESEARCH COUNCIL - NRC. 1996. Nutrient requirements of beef cattle. 7.ed. Washington, D.C. 404p.

PEREIRA, L.P. Desenvolvimento ponderal em peso e medidas corporais de bovinos de corte inteiros ou castrados de diferentes grupos genéticos: Santa Maria, RS : UFSM, 1999. 90p. Dissertação (Mestrado em Zootecnia) - Universidade Federal de Santa Maria, 1999.

RESTLE, J., FELTEN, H., VAZ, F.N. 1995. Efeito da raça e heterose para desempenho em confinamento de novilhos de corte. Rev. Argen. Prod. Anim., 15(3):852-859.

RESTLE, J., FLORES, J.L.C., VAZ, F.N. et al. 1997. Desempenho em confinamento, do desmame ao abate aos quatorze meses, de bovinos inteiros ou castrados, produzidos por vacas de dois anos. Ciência Rural, 27(4):651-655.

RESTLE, J., GRASSI, C., FEIJÓ, G.L.D. 1994a. Evolução do peso de bovinos de corte inteiros ou castrados em diferentes idades. Pesq. Agropec. Bras., 29(10):1631-1635.

RESTLE, J., GRASSI, C., FEIJÓ, G.L.D. 1994b. Características de carcaça de bovinos de corte inteiros ou castrados em diferentes idades. Pesq. Agropec. Bras., 29(10):1603-1607.

RESTLE, J., GRASSI, C., FEIJÓ, G.L.D. 1996. Desenvolvimento e rendimento de carcaça de bovinos inteiros ou submetidos a duas formas de castração, em condições de pastagem. R. Soc. Bras. Zootec., 25(2):324-333.

RESTLE, J., POLLI, V.A., ALVES FILHO, D.C. et al. 1999. Desenvolvimento de bovinos de corte de diferentes grupos genéticos desmamados aos 3 ou 7 meses de idade. Rev. bras. zootec., 28(5):1023-1030.

RESTLE, J., VAZ, F.N. 1999. Confinamento de bovinos definidos e cruzados. In: LOBATO, J.F.P., BARCELLOS, J.O.J., KESSLER, A.M. (Eds.) Produção de bovinos de corte. Porto Alegre: EDIPUCRS. 1.ed. p.141-167.

SAS Institute Inc., SAS/STAT. 1993. User's guide: statistic. Version 6, 4.ed., v.2. Cary: SAS Institute Inc.

Recebido em: 28/09/1999

Aceito em: 30/11/1999 